\title{
Proximal Femoral Nail versus Dynamic Hip Screw Fixation for Trochanteric Fractures: A Meta-Analysis of Randomized Controlled Trials
}

\author{
Xiao Huang, ${ }^{1}$ Frankie Leung, ${ }^{2}$ Zhou Xiang, ${ }^{1}$ Pei-Yong Tan, ${ }^{1}$ Jing Yang, \\ Dai-Qing Wei, ${ }^{1}$ and Xi Yu ${ }^{1}$ \\ ${ }^{1}$ Department of Orthopaedics, West China Hospital, Sichuan University, No. 37 Guoxue Xiang, Chengdu, \\ Sichuan 610041, China \\ ${ }^{2}$ Department of Orthopaedics and Traumatology, Queen Mary Hospital, The University of Hong Kong, Hong Kong
}

Correspondence should be addressed to Zhou Xiang; xiangzhou15@hotmail.com

Received 26 October 2012; Accepted 9 December 2012

Academic Editors: S. P. Grogan, M. Hedström, and V. Jansson

Copyright (c) 2013 Xiao Huang et al. This is an open access article distributed under the Creative Commons Attribution License, which permits unrestricted use, distribution, and reproduction in any medium, provided the original work is properly cited.

Background. The purpose of this meta-analysis was to find out whether the proximal femoral nail was better than the dynamic hip screw in the treatment of trochanteric fractures with respect to operation time, blood transfusion, hospital stay, wound complications, number of reoperation, and mortality rate. Methods. All randomized controlled trials comparing proximal femoral nail and dynamic hip screw in the treatment of trochanteric fractures were included. Articles and conference data were extracted by two authors independently. Data was analyzed using RevMan 5.1 version. Eight trials involving 1348 fractures were retrieved. Results. Compared with DHS fixation, PFN fixation had similar operation time (95\% CI: $-15.28-2.40, P=0.15)$. Blood loss and transfusion during perioperative time were also comparable between the two fixations (95\% CI: $-301.39-28.11, P=0.10$; 95\% CI: $-356.02-107.20, P=0.29$, resp.). Outcomes of hospital stay (95\% CI: $-0.62-1.01, P=0.64)$, wound complication (95\% CI: 0.66-1.67, $P=0.82$ ), mortality (95\% CI: $0.83-1.30, P=0.72$ ), and reoperation (95\% CI: $0.61-1.54, P=0.90$ ) were all similar between the two groups. Conclusion. PFN fixation shows the same effectiveness as DHS fixation in the parameters measured.

\section{Introduction}

The incidence of the hip fracture has been rising with an aging population in many parts of the world, and the number of hip fractures is expected to reach 512,000 in the year 2040 [1].

Hip fractures include mainly trochanteric and femoral neck fractures, and the former was reported with a mortality rate ranging from $15 \%$ to $30 \%$ in America [2]. Surgical treatment with stable fixation allows early mobilization and reduces complications. There are two main types of fixations for trochanteric fractures, which are plate fixation and intramedullary implants $[3,4]$. Dynamic hip screw (DHS) or sliding hip screw (SHS) has been the standard implant in treating trochanteric fractures [5-10]. However, when compared with the intramedullary implants, it has a biomechanical disadvantage because of a wider distance between the weight bearing axis and the implants [11]. The proximal femoral nail (PFN) introduced by the AO/ASIF group in 1998 has become prevalent in treating trochanteric fractures in recent years [12-15]. Although there were several reports showing benefits of proximal femoral nail [16-18], it was still associated with technical failures $[19,20]$. The cost of PFN is also much more than DHS.

Therefore, we conducted a meta-analysis to investigate whether there is a significant difference between PFN and DHS fixation in treating trochanteric fractures. The hypothesis is that PFN fixation is not more effective than DHS fixation in terms of decreasing operation time and blood transfusion, as well as reducing hospital stay, wound complication, reoperation, and mortality.

\section{Methods}

2.1. Search Strategies. The database for search included the Cochrane library, OVID, MEDLINE, EMBASE, and CNKI (China National Knowledge Infrastructure) from January 
1998 to October 2012. Single or combinations of terms were searched as follows: dynamic hip screw, DHS, dynamic compression hip screw, sliding hip screw, SHS, proximal femoral nail, and PFN.

2.2. Inclusion and Exclusion Criteria. Only prospective, randomized controlled trials (RCTs) and quasi-randomized controlled trials which compared the PFN fixation with the DHS fixation were selected. These studies enrolled patients with hip fractures classified as pertrochanteric or intertrochanteric without subtrochanteric extension by AO/OTA classification $[21,22]$. Patients with pathological fractures, fractures associated with polytrauma, or patients with previous ipsilateral hip or femur surgeries were excluded.

Targon PFN fixation was also included [25, 28], which offered a biaxial fixation of the proximal fragment [29], and was inserted in a similar method into the intramedullary cavity [10]. It was considered as a type of PFN implant.

If there were duplicates or multiple publications from the same study, which had overlap in original information, the most complete results should be chosen. If studies included had insufficient information, the authors were contacted for original data.

2.3. Data Extraction and Quality Assessment. Data were extracted by two experienced researchers independently. Different opinions were resolved by discussion. The assessment method which the Cochrane Handbook provided was used to assess the randomization, allocation concealment (according to whether allocation concealment was adequate, unclear, inadequate, or not used as a criterion to assess validity), blinding, and follow-up coverage of the studies included [30]. The three levels were assessed as follows: level A, all the criteria were adequate, which had a low risk of bias; level $\mathrm{B}$, one or more of the criteria were not described, which had a moderate risk of bias; level $\mathrm{C}$, one or more of the criteria were incorrect, inadequate, or not used, which had a high risk of bias.

2.4. Data Analysis. The weighted mean difference was calculated for continuous outcomes, and the relative risks (RRs) were calculated for dichotomous outcomes, with both adopted a 95\% confidence interval (CI). The heterogeneity among studies was assessed using $I$-square $\left(I^{2}\right)$ test, Chisquare $\left(\chi^{2}\right)$ test, and Tau-square $\left(\tau^{2}\right)$ test. When there was no statistical heterogeneity (as judged by $\chi^{2}$ test $P \geq 0.1$ or $I^{2}<$ $50 \%$ ), a fixed effect model was adopted; otherwise, a random effect model was chosen. All analyses were performed by using the software Review Manager 5.1 [31]. A $P$ value of less than 0.05 was considered statistically significant.

\section{Results}

A total of 489 potentially relevant articles were retrieved: 25 from Cochrane library, 60 from MEDLINE, 114 from OVID, 137 from EMBASE, and 153 from CNKI. After excluding nonrandomized control trials and studies not comparing the proper implants and/or reporting inadequate data, eight randomized or quasi-randomized controlled trials were included (Figure 1). There were a total of 1348 patients who were predominantly elderly with trochanteric fractures. Five trials targeted Caucasian patients, and the other three targeted Asian ones. There were 675 patients treated by PFN and 673 by DHS. The baseline characterizations like age and gender were comparable in two groups (Table 1). Most studies evaluated operation time, blood loss, blood transfusion, wound complication, mortality, and reoperation. The quality of six studies included was level B for the allocation concealment, or the blinding was unclear according to the evaluation criteria mentioned above. The other two studies, one was level A which met all the criteria and another was level $\mathrm{C}$ because patients' medical record numbers, were used for allocation, and the allocation concealment was inadequate (Table 2).

3.1. Operation Time. All eight studies provided data of operation time, but the data of five studies were eligible in the form of mean and standard deviation (SD). There were 1100 fractures included, 547 patients with the PFN fixation and 553 with the DHS fixation (Table 3 ). The heterogeneity test indicated a statistical evidence of heterogeneity $\left(\chi^{2}=50.13\right.$, $\left.P<0.00001, I^{2}=92 \%\right)$. We pooled data by a random effect model which indicated that there was no statistical difference in operation time between the two groups. (mean difference: $-6.44,95 \% \mathrm{CI}:-15.28-2.40, P=0.15$ ) (Figure 2).

3.2. Blood Loss and Transfusion. There were two articles involving 172 fractures which provided data of blood loss (Table 3). The heterogeneity test indicated there was a statistical heterogeneity $\left(\chi^{2}=3.76, P=0.05, I^{2}=73 \%\right)$, and the outcome shows no significant difference of blood loss with PFN than with DHS (Mean Difference: -136.64, 95\% CI: $-301.39-28.11, P=0.10$ ) (Figure 3). There were four articles included with 978 fractures providing data for blood transfusion. No significant difference in the amount of blood transfusion between the PFN group and the DHS group was found (Mean Difference: -124.41, 95\% CI: -356.02-107.20, $P=0.29$ ) (Figure 4).

3.3. Hospital Stay. Five studies included data of hospital stay. There were a total of 608 patients, with 301 patients in the PFN group and 307 in the DHS group (Table 4). The heterogeneity test indicated no statistical heterogeneity $\left(\chi^{2}=3.96, P=\right.$ $\left.0.41, I^{2}=0 \%\right)$. Data pooled by a fixed effects model indicated that there was no statistical difference in hospital stay between the PFN group and DHS group (Mean Difference: $0.20,95 \%$ CI: $-0.62-1.01, P=0.64$ ) (Figure 5).

3.4. Wound Complication. Wound complications including wound infection, drainage, delayed healing, and hematoma were documented in seven studies while one showed no wound complication (Table 4 ). No statistical heterogeneity was presented by heterogeneity test $\left(\chi^{2}=3.54, P=0.62, I^{2}=\right.$ $0 \%)$. Data pooled by a fixed effect model showed no statistical 
TABLE 1: Characteristics of the included studies.

\begin{tabular}{|c|c|c|c|c|c|c|c|}
\hline \multirow{2}{*}{ Studies } & \multicolumn{2}{|c|}{ Ages (years) } & \multirow{2}{*}{ Men (\%) } & \multirow{2}{*}{ Setting } & \multirow{2}{*}{ Follow-up (months) } & \multirow{2}{*}{ Fracture type (OTA, 31-) } & \multirow{2}{*}{ Year } \\
\hline & PFN & DHS & & & & & \\
\hline Saudan et al. [23] & $83 \pm 9.7$ & $83.7 \pm 10.1$ & 22.3 & Switzerland & 12 & $\mathrm{~A} 1, \mathrm{~A} 2$ & 2002 \\
\hline Pan et al. [24] & $70 \pm 6.8$ & $69 \pm 7.1$ & 75 & China & $16(12-28)$ & $\mathrm{A} 1, \mathrm{~A} 2, \mathrm{~A} 3$ & 2004 \\
\hline Pajarinen et al. [18] & $80.9 \pm 9.1$ & $80.3 \pm 10.8$ & 25 & Finland & 4 & $\mathrm{~A}(1.1-1.2,2.1-2.2$, others $)$ & 2005 \\
\hline Giraud et al. [25] & $81 \pm 12.8$ & $82 \pm 9.8$ & 23 & France & 3 & $\mathrm{~A} 1, \mathrm{~A} 2, \mathrm{~A} 3$ & 2005 \\
\hline Papasimos et al. [26] & 79.4 & 81.4 & 38.8 & Greece & 12 & $\mathrm{~A} 2, \mathrm{~A} 3$ & 2005 \\
\hline Liu et al. [27] & $76 \pm 4.3$ & $78 \pm 4.5$ & 29.1 & China & 9 & $\mathrm{~A} 1, \mathrm{~A} 2$ & 2009 \\
\hline Huang et al. [17] & $75 \pm 5$ & $77 \pm 5$ & 26 & China & 9 & $\mathrm{~A} 1, \mathrm{~A} 2$ & 2010 \\
\hline Parker et al. [28] & $81.4(27-104)$ & $82.4(26-104)$ & 20.2 & UK & 12 & $\mathrm{~A} 1, \mathrm{~A} 2, \mathrm{~A} 3, \mathrm{~B} 2.1$ & 2012 \\
\hline
\end{tabular}

PFN: proximal femoral nail; DHS: dynamic hip screw; OTA: Orthopaedic Trauma Association.

TABLE 2: Methodological quality of included studies.

\begin{tabular}{|c|c|c|c|c|c|c|c|}
\hline \multirow{2}{*}{ Studies } & \multicolumn{2}{|c|}{ No. of fractures } & \multirow{2}{*}{ Randomization } & \multirow{2}{*}{ Allocation concealment } & \multirow{2}{*}{ Blinding } & \multirow{2}{*}{ Loss to follow-up } & \multirow{2}{*}{ Level } \\
\hline & PFN & DHS & & & & & \\
\hline Saudan et al. [23] & 100 & 106 & Adequate & Not described & Not described & Yes & $\mathrm{B}$ \\
\hline Pan et al. [24] & 30 & 34 & Inadequate & Inadequate & Adequate & Yes & $\mathrm{C}$ \\
\hline Pajarinen et al. [18] & 54 & 54 & Adequate & Adequate & Not described & Yes & B \\
\hline Giraud et al. [25] & 34 & 26 & Adequate & Not described & Not described & Yes & B \\
\hline Papasimos et al. [26] & 40 & 40 & Not described & Not described & Not described & Yes & B \\
\hline Liu et al. [27] & 69 & 65 & Not described & Not described & Not described & Yes & $\mathrm{B}$ \\
\hline Huang et al. [17] & 48 & 48 & Adequate & Adequate & Not described & Yes & B \\
\hline Parker et al. [28] & 300 & 300 & Adequate & Adequate & Adequate & Yes & A \\
\hline
\end{tabular}

Loss to follow-up: reported patients loss to follow-up.

TABLE 3: Intraoperative outcomes of the two groups.

\begin{tabular}{|c|c|c|c|c|c|c|}
\hline \multirow{2}{*}{ Studies } & \multicolumn{2}{|c|}{ Operation time (min) } & \multicolumn{2}{|c|}{ Blood loss (mL) } & \multicolumn{2}{|c|}{ Blood transfusion $(\mathrm{mL})^{\mathrm{a}}$} \\
\hline & PFN & DHS & PFN & DHS & PFN & DHS \\
\hline Saudan et al. [23] & $64 \pm 33$ & $65 \pm 26$ & NA & NA & $584 \pm 720$ & $692 \pm 704$ \\
\hline Pan et al. [24] & $59.16 \pm 16.92$ & $87.35 \pm 21.29$ & $273.33 \pm 120.8$ & $480.88 \pm 177.90$ & $466.6 \pm 137.19$ & $833 \pm 300$ \\
\hline Pajarinen et al. [18] & $55(35-200)$ & $45(20-105)$ & $320 \pm 310$ & $357 \pm 495$ & $1040 \pm 960$ & $1040 \pm 800$ \\
\hline Giraud et al. [25] & 35 & 42 & 410 & 325 & NA & NA \\
\hline Papasimos et al. [26] & $71.2(60-240)$ & $59.2(40-100)$ & 265 & 282.4 & NA & NA \\
\hline Liu et al. [27] & $46.5 \pm 20.5$ & $53.4 \pm 8.3$ & 136 & 152 & NA & NA \\
\hline Huang et al. [17] & $50.5 \pm 20.2$ & $52.4 \pm 18.3$ & 202.5 & 225 & 200 & 200 \\
\hline Parker et al. [28] & $49 \pm 12.7$ & $46 \pm 12.3$ & NA & NA & $140 \pm 220$ & $128 \pm 190$ \\
\hline
\end{tabular}

alood transfusion $(\mathrm{mL})$ had a unit conversion from original articles; NA: not available.

TABLE 4: Postoperative outcomes of the two groups.

\begin{tabular}{|c|c|c|c|c|c|c|c|c|}
\hline \multirow{2}{*}{ Studies } & \multicolumn{2}{|c|}{ Hospital stay (days) } & \multicolumn{2}{|c|}{ Wound complication ${ }^{\mathrm{b}}$} & \multicolumn{2}{|c|}{ Mortality $^{\mathrm{b}}$} & \multicolumn{2}{|c|}{ Reoperation $^{\mathrm{b}}$} \\
\hline & PFN & DHS & PFN & DHS & PFN & DHS & PFN & DHS \\
\hline Saudan et al. [23] & $13 \pm 4$ & $14 \pm 10$ & $11(11 \%)$ & $10(9.43 \%)$ & $21(21 \%)$ & $17(16.04 \%)$ & $11(11 \%)$ & $6(5.66 \%)$ \\
\hline Pan et al. [24] & $24.73 \pm 5.52$ & $25.56 \pm 5.32$ & $2(6.67 \%)$ & $4(11.76 \%)$ & $0(0 \%)$ & $0(0 \%)$ & $0(0 \%)$ & $0(0 \%)$ \\
\hline Pajarinen et al. [18] & $6.1 \pm 3.3$ & $5.4 \pm 3.0$ & $0(0 \%)$ & $0(0 \%)$ & $10(18.52 \%)$ & $11(20.37 \%)$ & $8(14.81 \%)$ & $11(20.37 \%)$ \\
\hline Giraud et al. [25] & 11 & 11 & NA & NA & $2(5.89 \%)$ & $1(3.85 \%)$ & $3(8.82 \%)$ & $0(0 \%)$ \\
\hline Papasimos et al. [26] & 8.8 & 9.9 & $4(10 \%)$ & $5(12.5 \%)$ & $1(2.5 \%)$ & $1(2.5 \%)$ & $5(12.5 \%)$ & $3(7.5 \%)$ \\
\hline Liu et al. [27] & $14 \pm 8.1$ & $15 \pm 8.3$ & $6(8.70 \%)$ & $2(3.08 \%)$ & $0(0 \%)$ & $0(0 \%)$ & $0(0 \%)$ & $0(0 \%)$ \\
\hline Huang et al. [17] & $12 \pm 5.1$ & $11 \pm 4.3$ & $5(10.42 \%)$ & $3(6.25 \%)$ & $0(0 \%)$ & $0(0 \%)$ & $0(0 \%)$ & $0(0 \%)$ \\
\hline Parker et al. [28] & $21.2(1-408)$ & $18.7(1-141)$ & $6(2 \%)$ & $9(3 \%)$ & $85(28.33 \%)$ & $85(28.33 \%)$ & $5(1.67 \%)$ & $13(4.33 \%)$ \\
\hline
\end{tabular}

The intention-to-treat analysis (ITT) was used in the analysis to reduce the withdrawal bias.

NA: not available. 


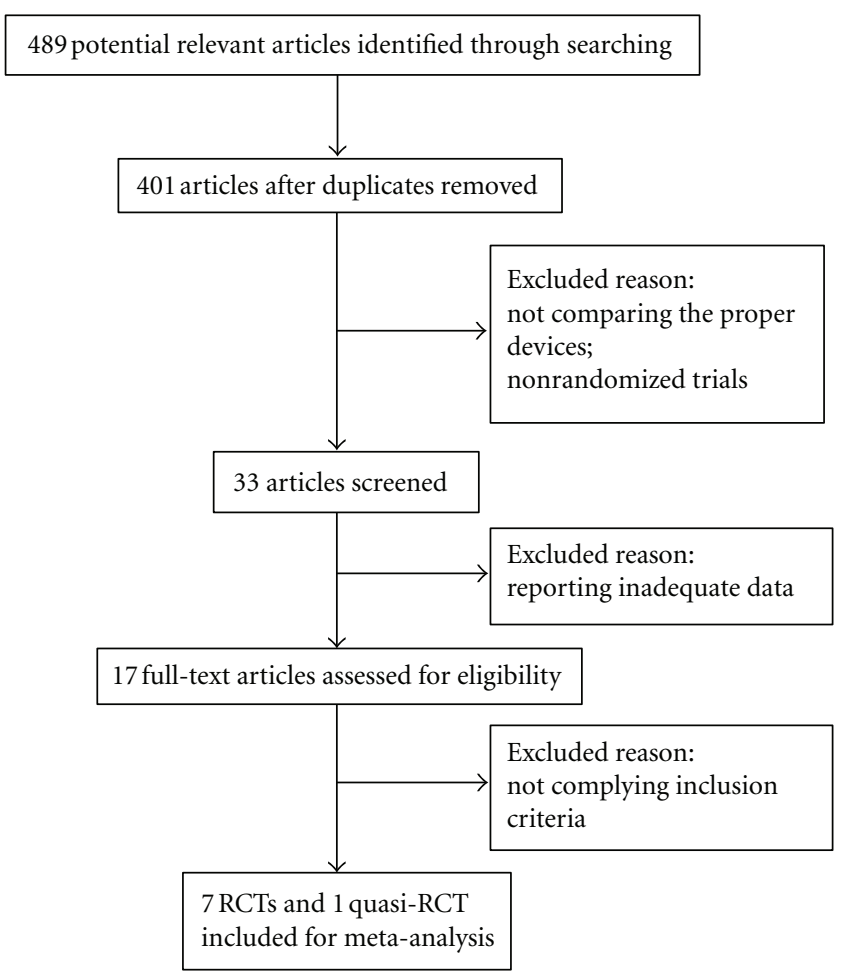

FIGURE 1: Flow diagram demonstrated methods for identification of studies and reasons for exclusion.

\begin{tabular}{|c|c|c|c|c|c|c|c|c|c|}
\hline \multirow{2}{*}{ Study or subgroup } & \multicolumn{3}{|c|}{ PFN } & \multicolumn{3}{|c|}{ DHS } & \multirow{2}{*}{ Weight } & \multirow{2}{*}{$\begin{array}{c}\text { Mean difference } \\
\text { IV, random, 95\% CI }\end{array}$} & \multirow{2}{*}{$\begin{array}{c}\text { Mean difference } \\
\text { IV, random, 95\% CI }\end{array}$} \\
\hline & Mean & $\mathrm{SD}$ & Total & Mean & SD & Total & & & \\
\hline Huang et al. 2010 & 50.5 & 20.2 & 48 & 52.4 & 18.3 & 48 & $19.4 \%$ & $-1.90[-9.61,5.81]$ & -1 \\
\hline Liu et al. 2009 & 46.5 & 20.5 & 69 & 53.4 & 8.3 & 65 & $21.0 \%$ & $-6.90[-12.14,-1.66]$ & - \\
\hline Saudan et al. 2002 & 64 & 33 & 100 & 65 & 26 & 106 & $19.0 \%$ & $-1.00[-9.14,7.14]$ & - \\
\hline Pan et al. 2004 & 59.16 & 16.92 & 30 & 87.35 & 21.29 & 34 & $18.1 \%$ & $-28.19[-37.56,-18.82]$ & - \\
\hline Parker et al. 2012 & 49 & 12.7 & 300 & 46 & 12.3 & 300 & $22.5 \%$ & $3.00[1.00,5.00]$ & - \\
\hline Total $(95 \%$ CI $)$ & & & 547 & & & 553 & $100.0 \%$ & $-6.44[-15.28,2.40]$ & \\
\hline \multirow{2}{*}{\multicolumn{9}{|c|}{$\begin{array}{l}\text { Heterogeneity: } \tau^{2}=89.53 ; \chi^{2}=50.13, \mathrm{df}=4(P<0.00001) ; I^{2}=92 \% \\
\text { Test for overall effect: } Z=1.43(P=0.15)\end{array}$}} & $-20-10 \quad 0 \quad 10 \quad 20$ \\
\hline & & & & & & & & & Favours PFN Favours DHS \\
\hline
\end{tabular}

FIGURE 2: Comparison of operation time between PFN and DHS.

\begin{tabular}{|c|c|c|c|c|c|c|c|c|c|}
\hline \multirow{2}{*}{ Study or subgroup } & \multicolumn{3}{|c|}{ PFN } & \multicolumn{3}{|c|}{ DHS } & \multirow{2}{*}{ Weight } & Mean difference & \multirow{2}{*}{$\begin{array}{c}\text { Mean difference } \\
\text { IV, random, 95\% CI }\end{array}$} \\
\hline & Mean & SD & Total & Mean & SD & Total & & IV, random, 95\% CI & \\
\hline Pajarinen et al. 2005 & 320 & 310 & 54 & 357 & 495 & 54 & $41.6 \%$ & $-37.00[-192.78,118.78]$ & - \\
\hline Pan et al. 2004 & 273.33 & 120.8 & 30 & 480.88 & 177.9 & 34 & $58.4 \%$ & $-207.55[-281.34$ & \\
\hline Total $(95 \%$ CI $)$ & & & 84 & & & 88 & $100.0 \%$ & $-136.64[-301.39,28.11]$ & \\
\hline \multicolumn{9}{|c|}{ Heterogeneity: $\tau^{2}=10676.46 ; \chi^{2}=3.76, \mathrm{df}=1(P=0.05) ; I^{2}=73 \%$} & $-500-250 \quad 0$ \\
\hline \multicolumn{7}{|c|}{ Test for overall effect: $Z=1.63(P=0.10)$} & & & Favours PFN Favours DHS \\
\hline
\end{tabular}

Figure 3: Comparison of blood loss between PFN and DHS. 


\begin{tabular}{|c|c|c|c|c|c|c|c|c|c|}
\hline \multirow{2}{*}{ Study or subgroup } & \multicolumn{3}{|c|}{ PFN } & \multicolumn{3}{|c|}{ DHS } & \multirow{2}{*}{ Weight } & \multirow{2}{*}{$\begin{array}{c}\text { Mean difference } \\
\text { IV, random, 95\% CI }\end{array}$} & \multirow{2}{*}{$\begin{array}{c}\text { Mean difference } \\
\text { IV, random, 95\% CI }\end{array}$} \\
\hline & Mean & SD & Total & Mean & SD & Total & & & \\
\hline Saudan et al. 2002 & 584 & 720 & 100 & 692 & 704 & 106 & $24.5 \%$ & $-108.00[-302.62,86.62]$ & - \\
\hline Pajarinen et al. 2005 & 1,040 & 960 & 54 & 1,040 & 800 & 54 & $18.4 \%$ & $0.00[-333.30,333.30]$ & \\
\hline Pan et al. 2004 & 466.6 & 137.19 & 30 & 833 & 300 & 34 & $27.7 \%$ & $-366.40[-478.55,-254.25]$ & ] $\square$ \\
\hline Parker et al. 2012 & 140 & 220 & 300 & 128 & 190 & 300 & $29.4 \%$ & $12.00[-20.89,44.89]$ & F \\
\hline Total $(95 \% \mathrm{CI})$ & & & 484 & & & 494 & $100.0 \%$ & $-124.41[-356.02,107.20]$ & \\
\hline \multicolumn{9}{|c|}{ Heterogeneity: $\tau^{2}=47143.58 ; \chi^{2}=41.08, \mathrm{df}=3(P<0.00001) ; I^{2}=93 \%$} & $-500-250$ \\
\hline \multicolumn{8}{|c|}{ Test for overall effect: $Z=1.05(P=0.29)$} & & Favours PFN Favours DHS \\
\hline
\end{tabular}

FIGURE 4: Comparison of blood transfusion between PFN and DHS.

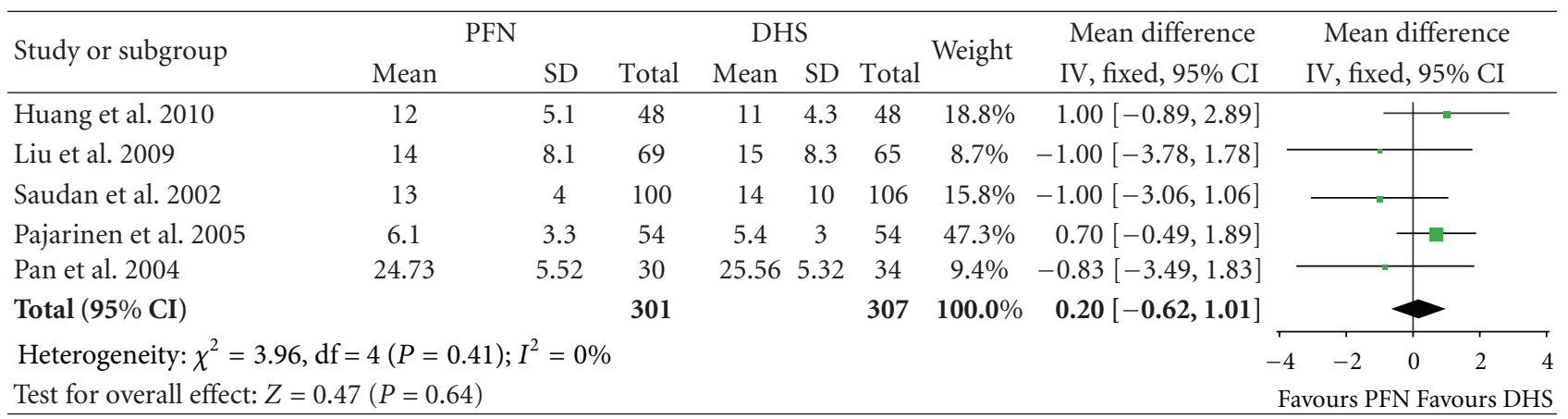

FIGURE 5: Comparison of hospital stay between PFN and DHS.

significant difference between the PFN group and the DHS group (RR: 1.05, 95\% CI: $0.66-1.67, P=0.82$ ) (Figure 6).

3.5. Mortality. All eight studies provided data of mortality, with three of them observed no death in both groups during the period from operation to the last follow-up (Table 4). The average follow-up duration of these studies was 9.6 (328) months. The heterogeneity test indicated no statistical evidence of heterogeneity $\left(\chi^{2}=0.92, P=0.92, I^{2}=0 \%\right)$, and data pooled by a fixed effect model indicated no statistical significant difference between the two groups (RR: 1.04, 95\% CI: 0.83-1.30, $P=0.72$ ) (Figure 7).

3.6. Reoperation. The reasons for reoperation mainly were cut-out of femoral head, redisplacement of the fractures, breakage of the implant, and nonunion. The average followup duration of these studies was 9.6 (3-28) months. All eight articles provided data of reoperation, with three of them had no case of reoperation before the last follow-up (Table 4). The heterogeneity test indicated no statistical heterogeneity $\left(\chi^{2}=7.59, P=0.11, I^{2}=47 \%\right)$, and data pooled by a fixed effect model indicated the outcome of reoperation was similar between the PFN group and the DHS group (RR: 0.97, 95\% CI: $0.61-1.54, P=0.90$ ) (Figure 8).

\section{Discussion}

The optimal fixation device for trochanteric fractures is still controversial at present. Jones et al. [32] compared the intramedullary nail (IMN), which involved gamma nail, intramedullary hip screw (IMHS), and PFN, with sliding hip screw for treatment of extracapsular proximal femoral fractures. They concluded that there was no statistically significant difference in the cut-out rate between the IMN and SHS while total failure rate and reoperation rate were greater with IMN. Parker and Handoll [10] also compared gamma and other cephalocondylic intramedullary nails with extramedullary implants for extracapsular hip fractures in adults. In their systematic review the authors enrolled four studies which included PFN and Targon PF nail compared with SHS. The authors concluded that there was no significant difference between the groups in outcomes of blood loss and transfusion, fixation complications, and post-operation complications and hospital stay.

This meta-analysis included eight RCTs, some of which were recently published and not included in previous metaanalysis and systematic review. We were able to show that PFN fixation and DHS fixation had similar effectiveness in the treatment of trochanteric fractures.

The analysis of operation time showed no significant difference between the two groups. But there was a notable heterogeneity, which could probably be explained by the 


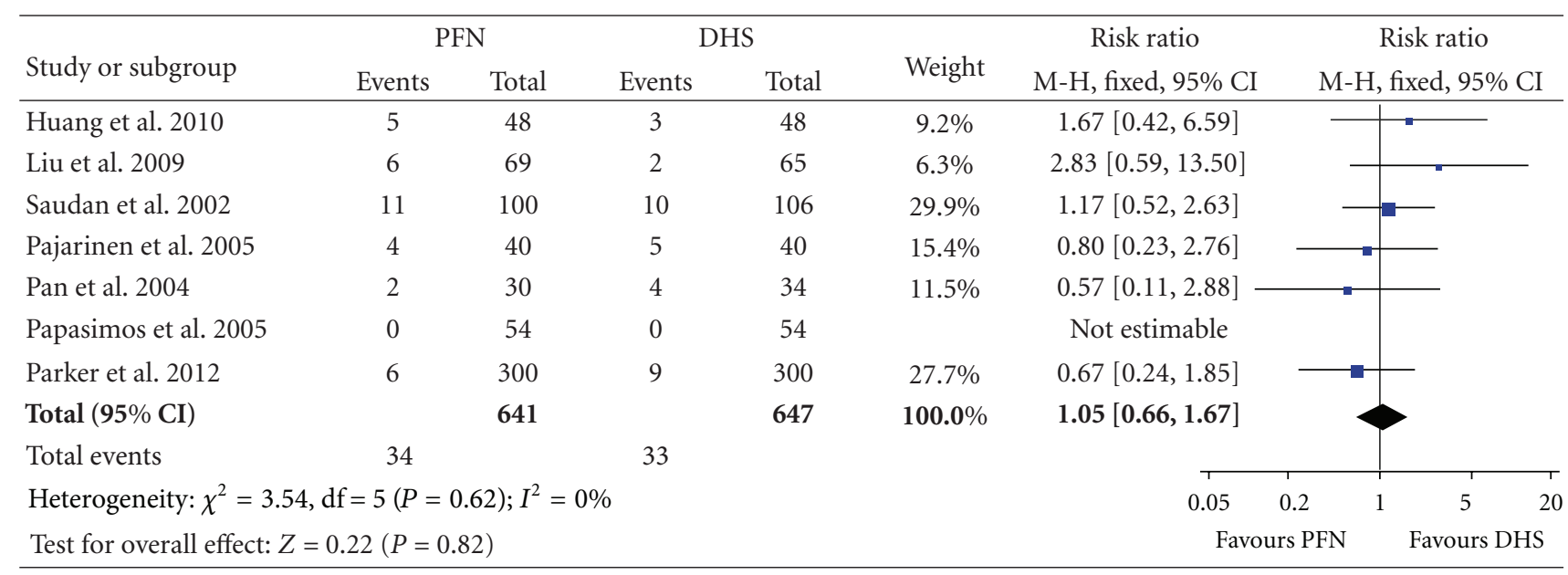

FIgURE 6: Comparison of wound complication between PFN and DHS.

\begin{tabular}{|c|c|c|c|c|c|c|c|}
\hline \multirow{2}{*}{ Study or subgroup } & \multicolumn{2}{|c|}{ PFN } & \multicolumn{2}{|c|}{ DHS } & \multirow{2}{*}{ Weight } & Risk ratio & \multirow{2}{*}{$\begin{array}{c}\text { Risk ratio } \\
\text { M-H, fixed, 95\% CI }\end{array}$} \\
\hline & Events & Total & Events & Total & & M-H, fixed, 95\% CI & \\
\hline Giraud et al. 2005 & 2 & 34 & 1 & 26 & \multirow[t]{3}{*}{$1.0 \%$} & $1.53[0.15,15.97]$ & \\
\hline Huang et al. 2010 & 0 & 48 & 0 & 48 & & Not estimable & \\
\hline Liu et al. 2009 & 0 & 69 & 0 & 65 & & Not estimable & \\
\hline Saudan et al. 2002 & 21 & 100 & 17 & 106 & $14.4 \%$ & $1.31[0.73,2.33]$ & - \\
\hline Pajarinen et al. 2005 & 10 & 54 & 11 & 54 & \multirow[t]{2}{*}{$9.6 \%$} & $0.91[0.42,1.96]$ & \\
\hline Pan et al. 2004 & 0 & 30 & 0 & 34 & & Not estimable & \\
\hline Papasimos et al. 2005 & 1 & 40 & 1 & 40 & $0.9 \%$ & $1.00[0.06,15.44]$ & \\
\hline Parker et al. 2012 & 85 & 300 & 85 & 300 & $74.1 \%$ & $1.00[0.78,1.29]$ & \\
\hline Total $(95 \% \mathrm{CI})$ & & 675 & & 673 & $100.0 \%$ & $1.04[0.83,1.30]$ & \\
\hline Total events & 119 & & 115 & & & & \\
\hline \multicolumn{5}{|c|}{ Heterogeneity: $\chi^{2}=0.92, \mathrm{df}=4(P=0.92) ; I^{2}=0 \%$} & & & \multirow{2}{*}{ 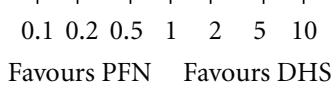 } \\
\hline \multicolumn{5}{|c|}{ Test for overall effect: $Z=0.36(P=0.72)$} & & & \\
\hline
\end{tabular}

Figure 7: Comparison of mortality between PFN and DHS.

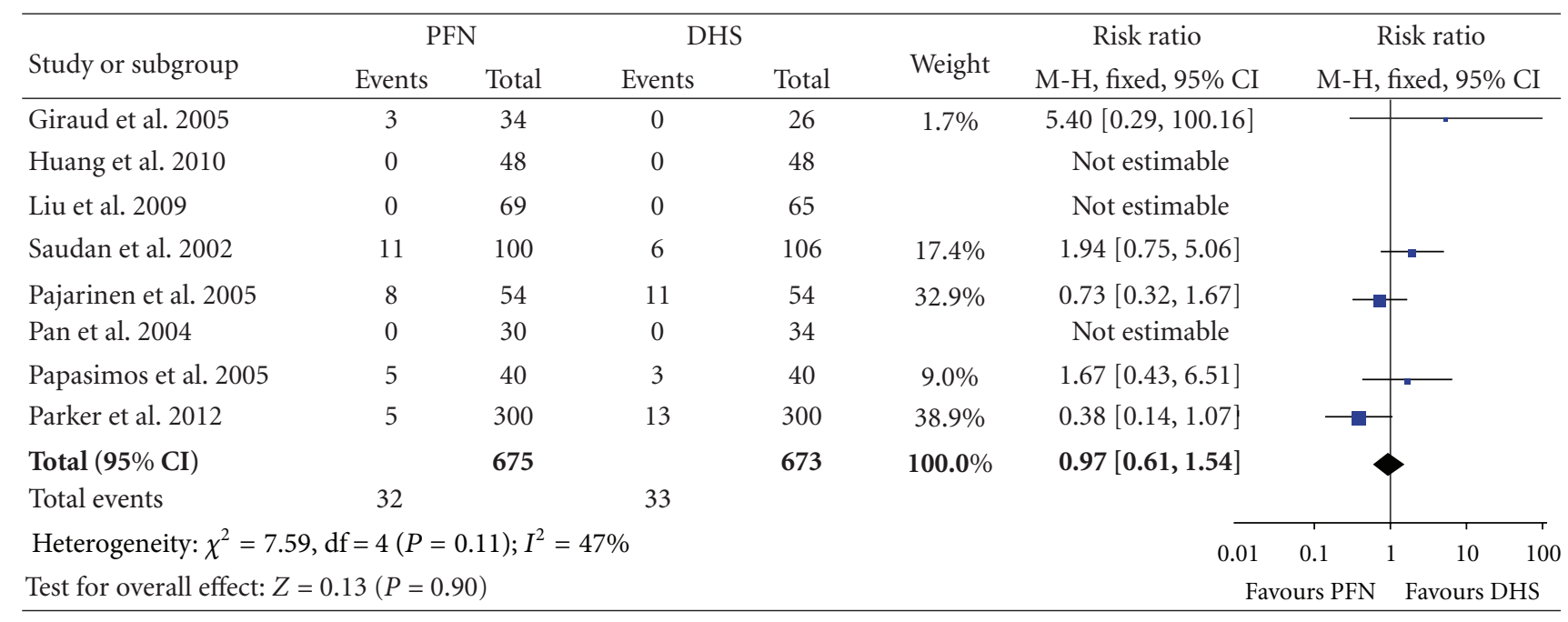

FIgURE 8: Comparison of reoperation between PFN and DHS. 
different levels of experience of surgeons, and the duration of PFN fixation could be shortened as surgical skills improved.

This paper showed no significant difference of blood loss and blood transfusion between the two implants. We could only find detailed outcomes related to blood loss and blood transfusion of four randomized studies from which data could be extracted. We enrolled studies of Pan et al. [24] and Pajarinen et al. [18] for analyzing blood loss and studies of Pan et al. [24], Pajarinen et al. [18], Parker et al. [28], and Saudan et al. [23] for blood transfusion. A sensitivity test was performed, which showed that, in blood transfusion, the two groups were still similar. In practice, various counting methods of blood loss were used in different hospitals, and surgeons usually estimate the blood loss. That could explain the statistic significant difference of heterogeneity $(P=0.01$, $\left.I^{2}=77 \%\right)$, which made it hard to draw any conclusion.

The intention-to-treat analysis (ITT) was used in the analysis of mortality and reoperation to reduce the withdrawal bias [33-36]. Furthermore, we tried to contact the authors of these studies for additional information but only received one response for checking the data of their research. This paper listed three cases of hematoma, one case of superficial wound infection, and one case of delayed wood healing in wound complications, but the author added it up to four [26]. Nevertheless, the outcome was still similar between the two groups when we performed a sensitivity test. It would be desirable if all the data from the studies were fully reported in a standard format, so that a larger sample can be analyzed to reduce bias.

There were some limitations in this meta-analysis. The number of studies included was not so adequate which just had eight studies involving 1348 fractures, and the quality of the trials was generally low. We intended to perform a subgroup analysis based on AO/OTA classification of the trochanteric fracture initially. Unfortunately, not all the studies provided precise classification of patients and had inadequate outcome data for extraction. Furthermore, different follow-up duration of included studies also reduced the power of our research.

In summary, PFN and DHS are equally effective in the treatment of trochanteric fractures. With future modifications to these two types of implants, more high-quality randomized controlled trials and further studies are needed to investigate whether these changes can lead to different outcomes.

\section{Conflict of Interests}

Dr. F. Leung received a research grant from Synthes. The remaining authors declare that they have no conflict of interests.

\section{Authors' Contribution}

F. Leung and Z. Xiang have equally contributed to this study.

\section{Acknowledgment}

This study was funded by the National Natural Science Foundation of China (Grant no. 30973049).

\section{References}

[1] S. R. Cummings, S. M. Rubin, and D. Black, "The future of hip fractures in the United States. Numbers, costs, and potential effects of postmenopausal estrogen," Clinical Orthopaedics and Related Research, no. 252, pp. 163-166, 1990.

[2] S. T. Canale and J. H. Beaty, Campbell's Operative Orthopaedics, St. Louis, Mo, USA, 11th edition edition, 2007.

[3] A. L. Utrilla, J. S. Reig, F. M. Muñoz, and C. B. Tufanisco, "Trochanteric gamma nail and compression hip screw for trochanteric fractures: a randomized, prospective, comparative study in 210 elderly patients with a new design of the gamma nail," Journal of Orthopaedic Trauma, vol. 19, no. 4, pp. 229-233, 2005.

[4] M. J. Parker and H. H. Handoll, "Gamma and other cephalocondylic intramedullary nails versus extramedullary implants for extracapsular hip fractures," Cochrane Database of Systematic Reviews, no. 1, Article ID CD000093, 2002.

[5] M. S. Butt, S. J. Krikler, S. Nafie, and M. S. Ali, "Comparison of dynamic hip screw and gamma nail: a prospective, randomized, controlled trial," Injury, vol. 26, no. 9, pp. 615-618, 1995.

[6] S. H. Bridle, A. D. Patel, M. Bircher, and P. T. Calvert, "Fixation of intertrochanteric fractures of the femur. A randomized prospective comparison of the gamma nail and the dynamic hip screw," Journal of Bone and Joint Surgery B, vol. 73, no. 2, pp. 330-334, 1991.

[7] P. R. Goldhagen, D. R. O'Connor, D. Schwarze, and E. Schwartz, "A prospective comparative study of the compression hip screw and the gamma nail," Journal of Orthopaedic Trauma, vol. 8, no. 5, pp. 367-372, 1994.

[8] C. W. Hoffman and T. G. Lynskey, "Intertrochanteric fractures of the femur: a randomized prospective comparison of the gamma nail and the ambi hip screw," Australian and New Zealand Journal of Surgery, vol. 66, no. 3, pp. 151-155, 1996.

[9] P. J. Radford, M. Needoff, and J. K. Webb, "A prospective randomised comparison of the dynamic hip screw and the gamma locking nail," Journal of Bone and Joint Surgery B, vol. 75, no. 5, pp. 789-793, 1993.

[10] M. J. Parker and H. H. Handoll, "Gamma and other cephalocondylic intramedullary nails versus extramedullary implants for extracapsular hip fractures in adults," Cochrane Database of Systematic Reviews, vol. 16, no. 3, Article ID CD000093, 2010.

[11] J. Anand, The Elements of Fracture Fixation, Churchill Livingstone, New York, NY, USA, 1997.

[12] H. Banan, A. Al-Sabti, T. Jimulia, and A. J. Hart, "The treatment of unstable, extracapsular hip fractures with the AO/ASIF proximal femoral nail (PFN) - our first 60 cases," Injury, vol. 33, no. 5, pp. 401-405, 2002.

[13] I. B. Schipper, S. Bresina, D. Wahl, B. Linke, A. B. Van Vugt, and E. Schneider, "Biomechanical evaluation of the proximal femoral nail," Clinical Orthopaedics and Related Research, no. 405, pp. 277-286, 2002.

[14] G. Al-yassari, R. J. Langstaff, J. W. M. Jones, and M. Al-Lami, "The AO/ASIF proximal femoral nail (PFN) for the treatment of unstable trochanteric femoral fracture," Injury, vol. 33, no. 5, pp. 395-399, 2002. 
[15] W. M. Gadegone and Y. S. Salphale, "Proximal femoral nailan analysis of 100 cases of proximal femoral fractures with an average follow up of 1 year," International Orthopaedics, vol. 31, no. 3, pp. 403-408, 2007.

[16] S. Nuber, T. Schönweiss, and A. Rüter, "Stabilisation of x hip screw (DHS) with trochanteric stabilisation plate vs. proximal femur nail (PFN)," Unfallchirurg, vol. 106, no. 1, pp. 39-47, 2003.

[17] Z. Y. Huang, X. W. Liu, and J. C. Su, "Dynamic hip screw vs. proximal femur nail in treatment of intertrochanteric fractures in patients aged over 70 years old," Shanghai Medical Journal, vol. 33, no. 11, 1042 pages, 2010.

[18] J. Pajarinen, J. Lindahl, O. Michelsson, V. Savolainen, and E. Hirvensalo, "Pertrochanteric femoral fractures treated with a dynamic hip screw or a proximal femoral nail: a randomised study comparing post-operative rehabilitation," Journal of Bone and Joint Surgery B, vol. 87, no. 1, pp. 76-81, 2005.

[19] R. E. S. Pires, E. O. Santana, L. E. N. Santos, V. Giordano, D. Balbachevsky, and F. B. dos Reis, "Failure of fixation of trochanteric femur fractures: clinical recommendations for avoiding Z-effect and reverse Z-effect type complications," Patient Safety in Surgery, vol. 5, no. 1, article 17, pp. 1-6, 2011.

[20] T. Pavelka, J. Matějka, and H. Červenková, "Complications of internal fixation by a short proximal nail," Acta Chirurgiae Orthopaedicae et Traumatologiae Cechoslovaca, vol. 72, no. 6, pp. 344-354, 2005.

[21] M. E. Müller, S. Nazarian, P. Koch, and J. Schatzker, The Comprehensive Classification of Fractures of Long Bones, Springer, New York, NY, USA, 1990.

[22] J. L. Marsh, T. F. Slongo, J. Agel et al., "Fracture and dislocation classification compendium-2007: orthopaedic trauma association classification, database and outcomes committee," Journal of Orthopaedic Trauma, vol. 21, supplement 10, pp. S1-S133, 2007.

[23] M. Saudan, A. Lübbeke, C. Sadowski, N. Riand, R. Stern, and P. Hoffmeyer, "Petrochanteric fractures: is there an advantage to an intramedullary nail? A randomized, prospective study of 206 patients comparing the dynamic hip screw and proximal femoral nail," Journal of Orthopaedic Trauma, vol. 16, no. 6, pp. 386-393, 2002.

[24] X. Pan, D. Xiao, B. Lin, and G. Huang, "Dynamic hip screws (DHS) and proximal femoral nails (PFN) in treatment of intertrochanteric fractures of femur in elderly patients," Chinese Journal of Orthopaedic Trauma, vol. 6, no. 7, pp. 785-789, 2004.

[25] B. Giraud, E. Dehoux, N. Jovenin et al., "Pertrochanteric fractures: a randomized prospective study comparying dynamic screw plate and intramedullary fixation," Revue de Chirurgie Orthopedique et Reparatrice de l'Appareil Moteur, vol. 91, no. 8, pp. 732-736, 2005.

[26] S. Papasimos, C. M. Koutsojannis, A. Panagopoulos, P. Megas, and E. Lambiris, "A randomised comparison of AMBI, TGN and PFN for treatment of unstable trochanteric fractures," Archives of Orthopaedic and Trauma Surgery, vol. 125, no. 7, pp. 462-468, 2005.

[27] X. W. Liu, C. C. Zhang, J. C. Su, Q. G. Fu, B. Q. Yu, and S. G. Xu, "Treatment of trochanteric fractures of eldly with dynamic hip screw and proximal femoral nail (single center, randomized and prospective research)," Chinese Journal of Bone and Joint Injury, vol. 24, no. 9, pp. 796-797, 2009 (Chinese).

[28] M. Parker, T. Bowers, and G. Pryor, "Sliding hip screw versus the targon PF nail in the treatment of trochanteric fractures of the hip: a randomised trial of 600 fractures," Journal of Bone and Joint Surgery B, vol. 94, no. 3, pp. 391-397, 2012.
[29] R. Biber, S. Grüninger, K. Singler, C. Sieber, and H. Bail, "Is proximal femoral nailing a good procedure for teaching in orthogeriatrics?" Archives of Orthopaedic and Trauma Surgery, vol. 132, no. 7, pp. 1-6, 2012.

[30] J. Higgins and S. Green, Cochrane Handbook for Systematic Reviews of Interventions, Version 5. 1. 0, 2011.

[31] Review Manager (RevMan), Version 5. 1. Copenhagen: The Nordic Cochrane Centre, The Cochrane Collaboration, 2011.

[32] H. W. Jones, P. Johnston, and M. Parker, "Are short femoral nails superior to the sliding hip screw? A meta-analysis of 24 studies involving 3,279 fractures," International Orthopaedics, vol. 30, no. 2, pp. 69-78, 2006.

[33] V. M. Montori and G. H. Guyatt, "Intention-to-treat principle," Canadian Medical Association Journal, vol. 165, no. 10, pp. 13391341, 2001.

[34] D. Moher, K. F. Schulz, and D. G. Altman, "The CONSORT statement: revised recommendations for improving the quality of reports of parallel group randomized trials," BMC Medical Research Methodology, vol. 1, no. 1, p. 2, 2001.

[35] G. H. Guyatt, D. L. Sackett, D. J. Cook et al., "Users' guide to the medical literature," The Journal of the American Medical Association, vol. 270, no. 21, pp. 2598-2601, 1993.

[36] L. B. Sheiner and D. B. Rubin, "Intention-to-treat analysis and the goals of clinical trials," Clinical Pharmacology and Therapeutics, vol. 57, no. 1, pp. 6-15, 1995. 


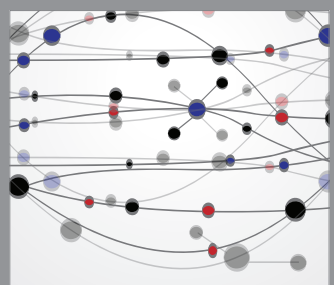

The Scientific World Journal
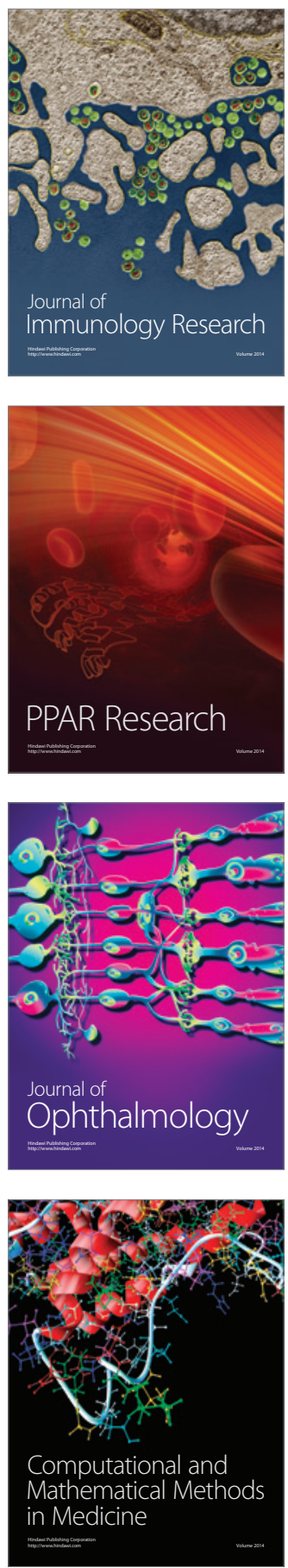

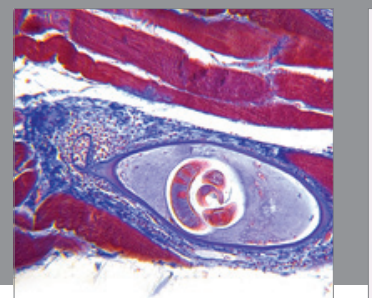

Gastroenterology

Research and Practice
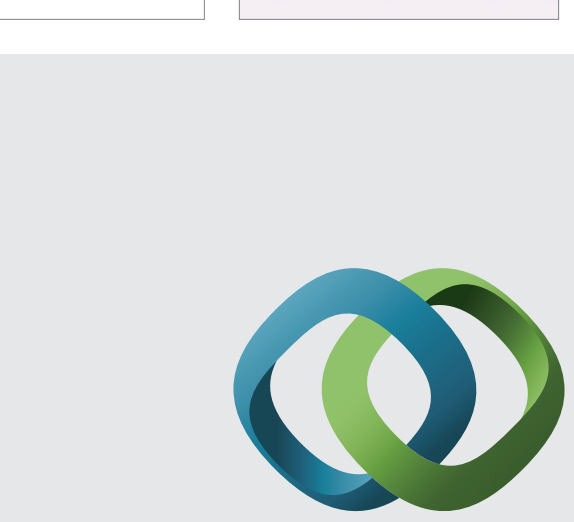

\section{Hindawi}

Submit your manuscripts at

http://www.hindawi.com
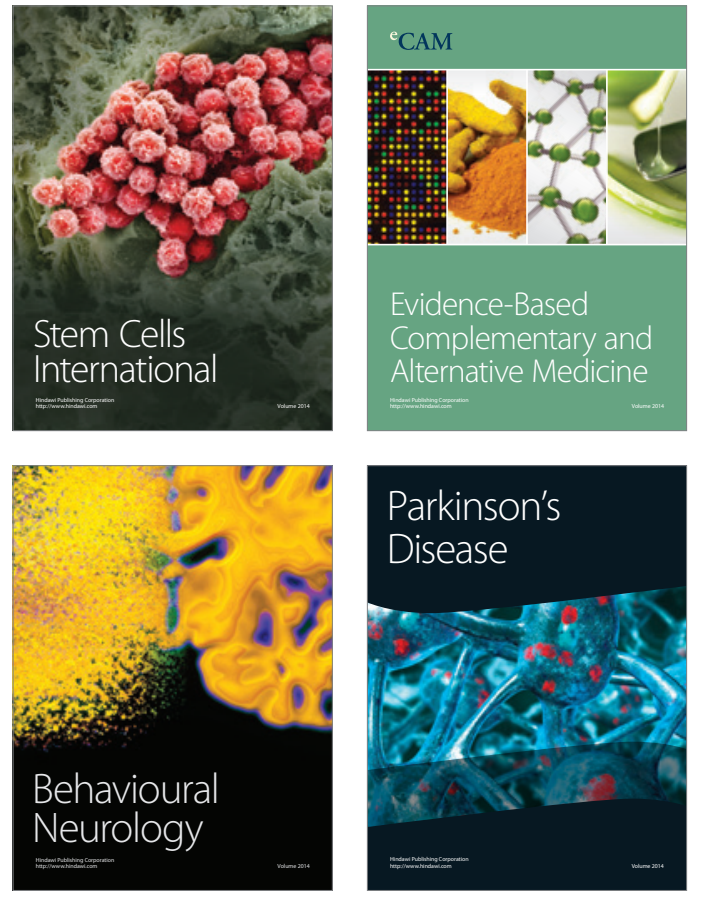
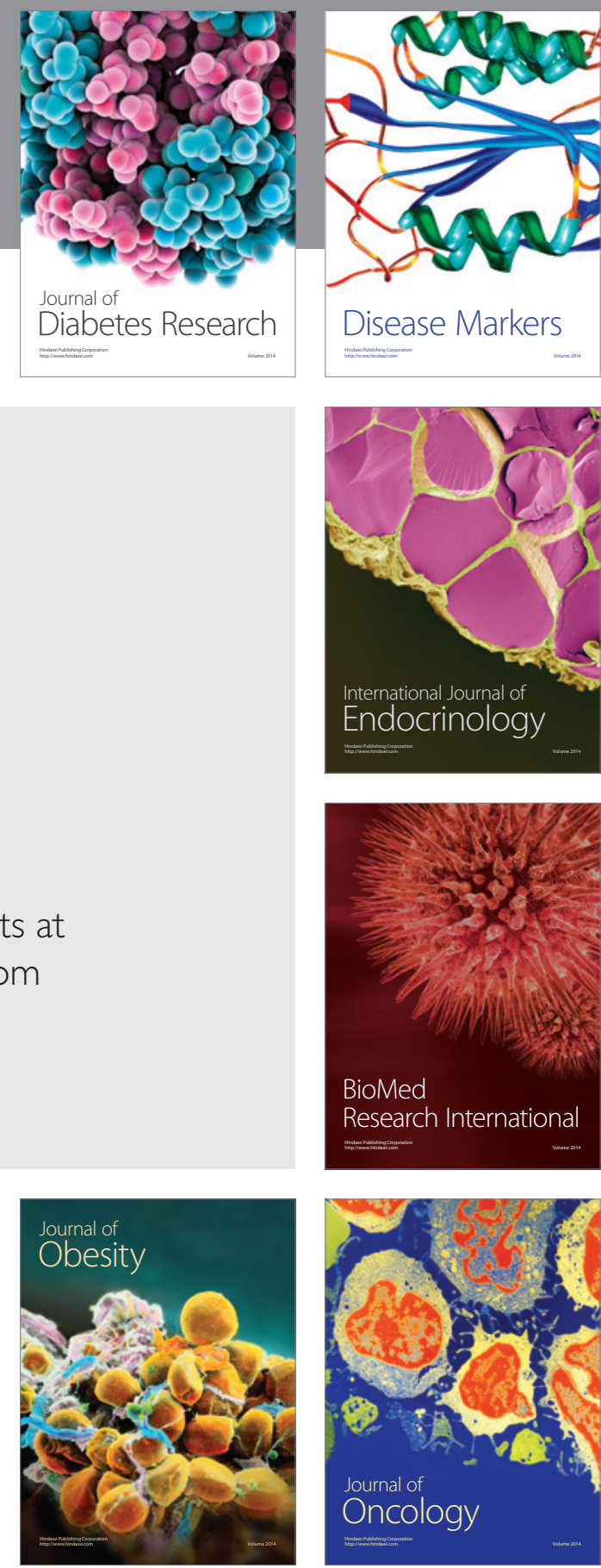

Disease Markers
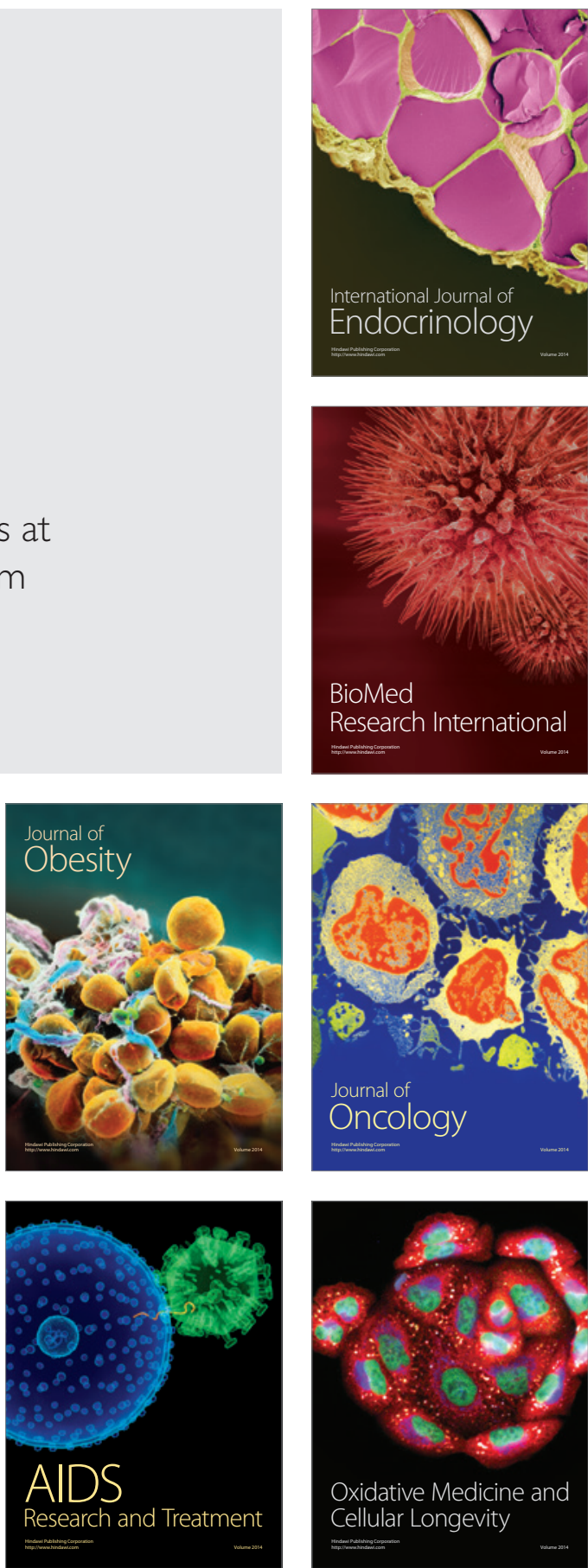